\title{
Antiangiogenic versus cytotoxic therapeutic approaches in a mouse model of pancreatic cancer: An experimental study with a multitarget tyrosine kinase inhibitor (sunitinib), gemcitabine and radiotherapy
}

\author{
VEERLE F. CASNEUF ${ }^{1}$, PIETER DEMETTER ${ }^{2}$, TOM BOTERBERG ${ }^{3}$, \\ LOUKE DELRUE $^{4}$, MARC PEETERS $^{1}$ and NANCY VAN DAMME ${ }^{1}$

\begin{abstract}
${ }^{1}$ Department of Gastroenterology, Ghent University Hospital, De Pintelaan 185, 9000 Gent; ${ }^{2}$ Department of Pathology, Université Libre de Bruxelles (ULB), Lenniksebaan 808, 1070 Brussels; Departments of ${ }^{3}$ Radiotherapy, and ${ }^{4}$ Radiology, Ghent University Hospital, De Pintelaan 185, 9000 Gent, Belgium
\end{abstract}

Received December 1, 2008; Accepted January 20, 2009

DOI: $10.3892 /$ or_00000412

\begin{abstract}
This work evaluated SU11248 (sunitinib) as a potential therapeutic agent, alone or in combination with the cytotoxic agent gemcitabine or radiotherapy in a murine model of pancreatic cancer. Panc02 cells were injected subcutaneously into HsdOla/MF1 mice $(n=222)$. Treatment was administered during 1 week: sunitinib (SUN), gemcitabine (GEM), radiotherapy (RT), RT+SUN and GEM+SUN. Mice were sacrificed 14 days after treatment. The effect on microvessel density (MVD) was measured by CD31 staining. Apoptosis (sFAS, cleaved caspase-3) and proangiogenic proteins (VEGF, PlGF, EGF) were measured with ELISA and immunohistochemistry. At day 14 , tumors in all groups increased significantly despite treatment. Only after RT/SUN treatment tumor growth slowed down, although the accretion was still significant $(\mathrm{P}=0.033)$. Highest levels of apoptosis were seen in GEM/SUN, RT/SUN and RT treated mice (respectively $\mathrm{P}<0.001, \mathrm{P}<0.01$ and $\mathrm{P}<0.05$ compared to placebo). MVD was lowest in RT/SUN treated mice [compared to placebo $(\mathrm{P}<0.05)$, GEM $(\mathrm{P}<0.05)$ and GEM/SUN $(\mathrm{P}<0.01)]$. Highest VEGF levels were seen after RT and RT/SUN treatment [vs. placebo $(\mathrm{P}<0.001)$ and vs. other treatments $(\mathrm{P}<0.01$ for all comparisons)]. GEM and SUN in monotherapy lead to an up-regulation of PIGF and EGF, respectively. In conclusion, the combination treatments $\mathrm{RT} / \mathrm{SUN}$ and GEM/SUN result in a more potent antiangiogenic and antitumor effect when compared to either treatment alone. Multitargeted angiogenesis inhibitor
\end{abstract}

Correspondence to: Dr Veerle F. Casneuf, Department of Gastroenterology, Ghent University Hospital, De Pintelaan 185, 9000 Gent, Belgium

E-mail: veerle.casneuf@ugent.be

Key words: pancreatic cancer, sunitinib, radiotherapy, gemcitabine therapy with sunitinib combined with either radiotherapy or gemcitabine may be a novel approach for human pancreatic cancer.

\section{Introduction}

Pancreatic cancer (PC) is one of the most lethal cancers in humans, with a 5-year survival rate of only $5 \%$ (1). Aggressive local growth and early metastases are hallmarks of this disease, distinguishing this tumor type from other adenocarcinomas. Complete resection in an early stage is the only option for cure. Despite potentially curative resection for pancreatic adenocarcinoma, local relapse (liver, intraabdominal) occurs in 50-85\% of patients and results in a 5-year survival of $<20 \%(2-7)$. The frequency and pattern of recurrence make postoperative chemotherapy and/or radiation an important consideration. The available data from randomized clinical trials of adjuvant therapy suggest that chemoradiotherapy has no obvious advantage compared with chemotherapy alone (8). Chemotherapy with gemcitabine is effective and probably offers the best benefit-risk ratio of all currently available adjuvant treatment options (9-13). Patients with locally advanced disease have a dismal long-term prognosis due to its resistance to chemotherapy and radiotherapy (14). For irresectable tumors radiation is given in combination with 5-FU chemotherapy. Recent evidence suggests that concurrent gemcitabine and radiation yields similar outcomes (15). In metastatic PC gemcitabine was accepted as a first-line therapy based on the results of a single phase III study comparing gemcitabine with bolus 5-FU (16). However, gemcitabine has limited antitumor efficacy, with an objective response rate of only $10 \%$. Although the development of alternative gemcitabine schedules regimens are still ongoing, there is an urgent need for novel targets and strategies (17).

Targeted therapies like bevacizumab [vascular endothelial growth factor (VEGF) inhibitor] and cetuximab [epidermal growth factor (EGF) receptor (R) inhibitor] are not active in monotherapy in advanced $\mathrm{PC}$, neither when added to gem- 
citabine $(18,19)$. Recently, erlotinib (EGFR inhibitor) combined with gemcitabine has shown improvement on overall survival and obtained approval in USA and Europe (20). The redundancy of angiogenic pathways or the capacity of the tumor to switch to another pathway in response to treatment, might explain the lack of efficacy of a therapeutic strategy that targets a single angiogenic pathway (21). However, as recently shown in rectal cancer, targeted therapies may play a role as radiosensitizers (22). A recent phase I dose-escalation study in patients with locally advanced pancreatic cancer evaluated the toxicity of capecitabine and bevacizumab combined with radiotherapy (23). Acute toxicity was minimal and easily managed by reducing the dose of capecitabine without interruption or attenuation of either bevacizumab or radiation dose. Another trimodal therapy with gemcitabine, cetuximab and radiotherapy was evaluated in a phase II study in locally advanced pancreatic cancer. Preliminary results showed that $58 \%$ of patients were amenable for secondary potentially curative resection (24). Regarding the benefits of targeted therapy in the combined modality treatment using either radiotherapy or chemotherapy, it has become clear that this is an important novel strategy for the treatment of pancreatic cancer. These results seem to be very promising but need to be confirmed.

Sunitinib malate (SU11248) is a highly potent, selective inhibitor of certain receptor tyrosine kinases, including VEGFRs types 1-3 and platelet derived growth factor receptors (PDGFRs) $\alpha$ and $\beta$ (25). This drug has gained approval in advanced renal cell carcinoma and imatinib-resistant gastrointestinal stromal tumors, where it has shown an objective response rate and improved progression-free survival $(26,27)$. In animal models, sunitinib exhibits potent antitumor activity in glioblastoma, breast and lung tumors $(28,29)$. In human PC, VEGFRs types 1-3 and PDGFRs $\alpha$ and $\beta$ are expressed and have been correlated with poor prognosis (30-33). Also, recently, it was demonstrated in vitro and in vivo that sunitinib sensitized pancreatic cancer cells to the cytotoxic effects of radiation (34). Therefore the aim of our study was to explore the role of gemcitabine and sunitinib alone or in combination with radiotherapy in a mouse model of pancreatic cancer.

\section{Materials and methods}

Cell culture. Panc02 cells (a kind gift from Dr A. Märten, University of Heidelberg, Germany) were cultured in RPMI1640 medium (Invitrogen Corporation, Gibco, Merelbeke, Belgium) supplemented with $10 \%$ fetal calf serum (Invitrogen Corporation), $4 \mathrm{mM}$ L-glutamine, $50 \mu \mathrm{l} / \mathrm{ml}$ penicillin and $50 \mu \mathrm{g} / \mathrm{ml}$ streptomycin (Invitrogen Corporation) and incubated at $37^{\circ} \mathrm{C}$ in a humidified atmosphere of $5 \% \mathrm{CO}_{2}$ in air. When in exponential growth phase, the cells were harvested using trypsin/EDTA (Invitrogen Corporation), washed, suspended in phosphate-buffered saline (PBS) and counted.

Animals/subcutaneous tumor model. Four-to-six week old male HsdOla/MF1 mice (16-20 gr body weight) were purchased from Harlan Laboratories (Netherlands) and housed in a standard facility at the Department of Laboratory Medicine, Ghent University. All procedures were carried out in accordance to the guidelines and regulations for use and care of animals and approved by our local ethics committee for animal care, Faculty of Medicine, Ghent University.

One million cells were injected in the right hind leg of 222 mice. Each group ( $n=26-45$ mice per group) was randomly assigned to a different treatment regimen.

Drugs and treatments. Treatment was administered during 1 week, starting 10-14 days after tumor inoculation. The first day of treatment was assigned 'day 1'. Drug doses were used at a concentration that alone, or in combination with other drugs, did not cause drug-related deaths or weight loss of $>15 \%$. Control mice received placebo (saline $0.9 \%$ ) intraperitoneally (i.p.) $90 \mu 1,3$ times/week (days 1, 4, 7). Gemcitabine (GEM, Gemzar, Eli-Lilly) was administered at a dose of $60 \mathrm{mg} / \mathrm{kg}$ body weight (BW) (1.8 mg in $90 \mu \mathrm{l})$ i.p. 3 times/week (days 1, 4, 7). Sunitinib (SUN, Sutent, Pfizer) was administered i.p. at a dose of $40 \mathrm{mg} / \mathrm{kg} \mathrm{BW}(1.4 \mathrm{mg}$ in $200 \mu 1$ ) i.p. per day (SUN, days 1-7). Radiotherapy (RT) was delivered in 5 fractions of 5 Gy on days 1-5, to a cumulative dose of 25 Gy. Mice received sedation during RT [i.p. injection of mixture of $100 \mathrm{mg} / \mathrm{kg} \mathrm{BW}$ ketamine (Ketalar, Pfizer) and $10 \mathrm{mg} / \mathrm{kg}$ BW xylazine (Rompun, Bayer)]. Mice were placed in the prone position and a radiation field was simulated around the tumor on the tumor-bearing leg. Tissue-equivalent silicone bolus of $1 \mathrm{~cm}$ was placed on the tumor site, to prevent the build-up effect under the skin. Photon irradiation with 1 direct field at a source-skin distance of 1 meter was performed with a 5-MV linear accelerator (Elekta, Crawley, UK). When combined regimens were given [radiotherapy+ sunitinib, RT/SUN], [gemcitabine+sunitinib, GEM/SUN] the same doses and schemes as in monotherapy were combined. Growth of the subcutaneous tumors was evaluated using a vernier caliper. Results are shown as tumor surface area (defined as tumor width (max horizontal diameter) $\mathrm{x}$ tumor length (max vertical diameter), in $\mathrm{cm}^{2}$ ). Tumor growth was evaluated before therapy (day 0), after 1 week of therapy (day 7) and after an additional week without therapy (day 14). Mice were sacrificed at day 15.

Immunohistochemical determination of CD31 and cleaved caspase-3. Paraffin-embedded tissues were used for immunohistochemical analysis of CD31 and cleaved caspase- 3 . Sections $(4 \mu \mathrm{m})$ were mounted on SuperFrost ${ }^{\circledR}$ microscope slides (Menzel-Glaser, Braunschweig, Germany). Sections were deparaffinised in xylene, followed by treatment with a graded series of alcohol and rehydrated.

For CD31 staining, sections were treated with trypsin (Sigma-Aldrich, Bornem, Belgium) for $7 \mathrm{~min}$ at $37^{\circ} \mathrm{C}$ and washed with TBS (Tris-buffered saline). All samples were incubated with hydrogen peroxide in methanol for $20 \mathrm{~min}$ to block endogenous peroxidase and washed with TBS. Sections were incubated overnight on room temperature with rat antimouse CD31 (BD-Pharmingen, Erembodegem, Belgium, $1 / 150$ ), then incubated with peroxidase-labeled IgF (Dako Cytomation, CA, USA) and followed by amplification with the TSA Biotin System (PerkinElmer, Waltham, MA, USA). Sections were rinsed with distilled water, counterstained with Harris' haematoxylin for $5 \mathrm{sec}$ and mounted with universal mount. Control samples exposed to secondary antibody 

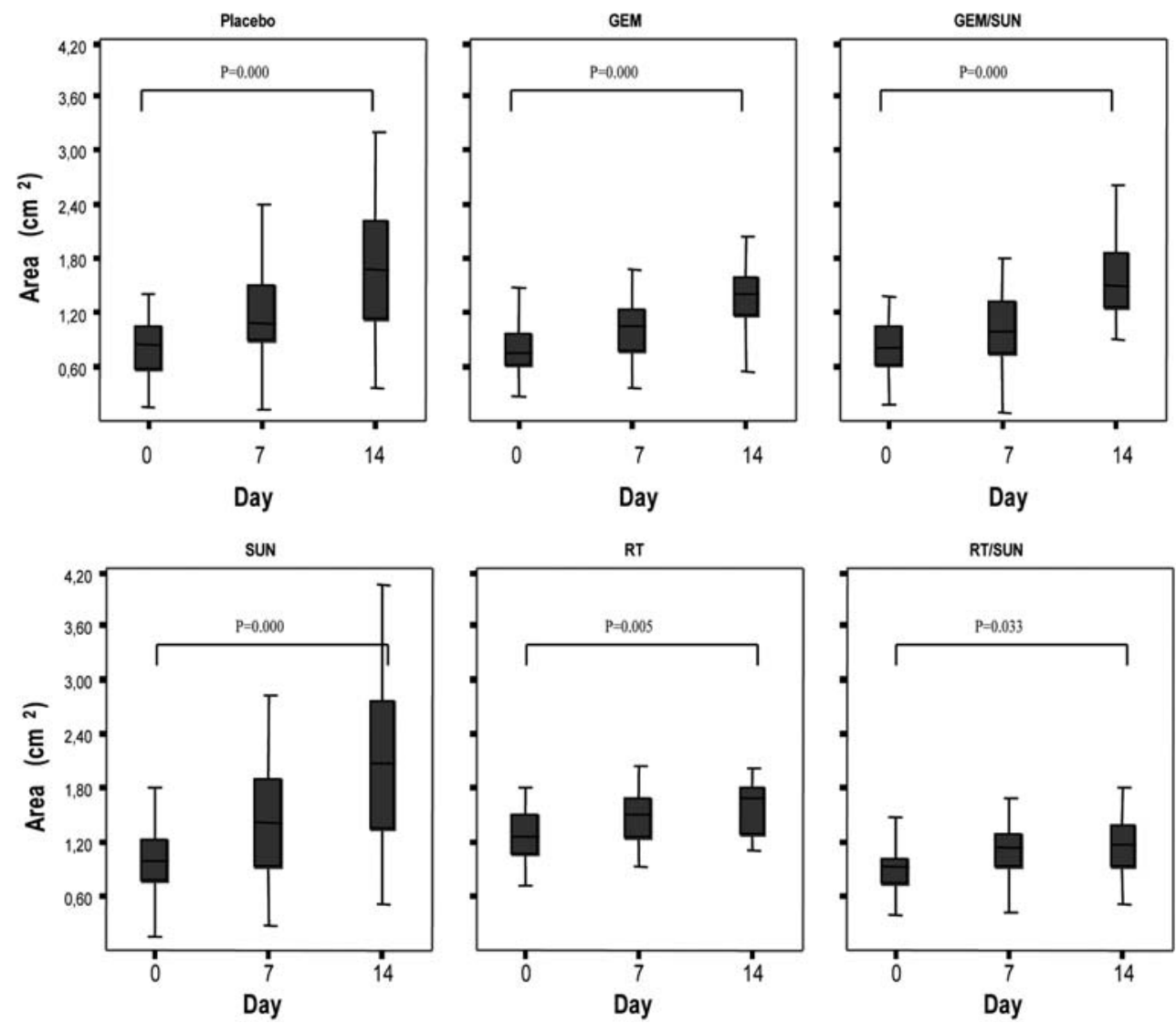

Figure 1. Tumor growth curve for different treatment strategies. Tumor surface area (in $\mathrm{cm}^{2}$ ), measured at 3 time points: day 0 , day 7 and day 14 for different treatment strategies. Therapy was administered between day 1 and day 7. GEM, gemcitabine; GEM/SUN, gemcitabine/sunitinib; SUN, sunitinib; RT, radiotherapy; RT/SUN, radiotherapy/sunitinib.

Table I. Tumor surface area in different treatment arms.

\begin{tabular}{lccccccc}
\hline Tumors $(\mathrm{n}=195)$ & Treatment & $\begin{array}{c}\text { Placebo } \\
(\mathrm{n}=45)\end{array}$ & $\begin{array}{c}\text { GEM } \\
(\mathrm{n}=34)\end{array}$ & $\begin{array}{c}\text { GEM/SUN } \\
(\mathrm{n}=26)\end{array}$ & $\begin{array}{c}\text { SUN } \\
(\mathrm{n}=32)\end{array}$ & $\begin{array}{c}\text { RT } \\
(\mathrm{n}=29)\end{array}$ & $\begin{array}{c}\text { RT/SUN } \\
(\mathrm{n}=29)\end{array}$ \\
\hline Area $\left(\mathrm{cm}^{2}\right)$ & Day 0 & 0.88 & 0.79 & 0.81 & 0.96 & 1.29 & 0.89 \\
& Day 7 & 1.22 & 1.02 & 1.01 & 1.47 & 1.42 & 1.09 \\
& Day 14 & 1.76 & 1.36 & 1.52 & 2.08 & 0.103 \\
\hline Day 0 vs Day 14 & P-value & 0.000 & 0.000 & 0.000 & 0.000 & 0.005 & 0.033 \\
\hline
\end{tabular}

GEM, gemcitabine; GEM/SUN, gemcitabine/sunitinib; SUN, sunitinib; RT, radiotherapy; RT/SUN, radiotherapy/sunitinib. P-values report differences in tumor surface area at day 0 compared with day 14.

alone showed no specific staining. For the quantification of microvessel density (MVD) in sections stained for CD31, the entire tumor section was scanned by 2 different readers (VC, PDM) at low power (magnification, x40) to identify hot spots, which are the areas of highest vascularization. Five hot spots were identified in the peripheral millimeter of the tumor, and 5 hot spots at the centre of the tumor. Individual microvessels were then counted under high power (magnification, $\mathrm{x} 200$ ) to obtain a vessel count in a defined area, and the average vessel count in the 10 hot spots was taken as the MVD.
For cleaved caspase-3 staining, after washing sections, heat induced antigen retrieval was performed for $10 \mathrm{~min}$ in citrate buffer ( $\mathrm{pH}$ 6.0), after which the tissue slides were cooled down for $30 \mathrm{~min}$. The endogenous peroxidase activity was blocked for $5 \mathrm{~min}$ with $0.3 \%$ hydrogen peroxide. After washing steps, each section was blocked with blocking solution (TBS/0.1\% Tween $/ 5 \%$ normal goat serum) for $1 \mathrm{~h}$ at room temperature. Primary antibody cleaved caspase-3 (Cell Signaling Technology, 1/400 dilution in PBS/0.1\% Tween/ $5 \%$ normal goat serum) was than incubated overnight at $4^{\circ} \mathrm{C}$. After washing, the tissue sections were incubated for $30 \mathrm{~min}$ 
A

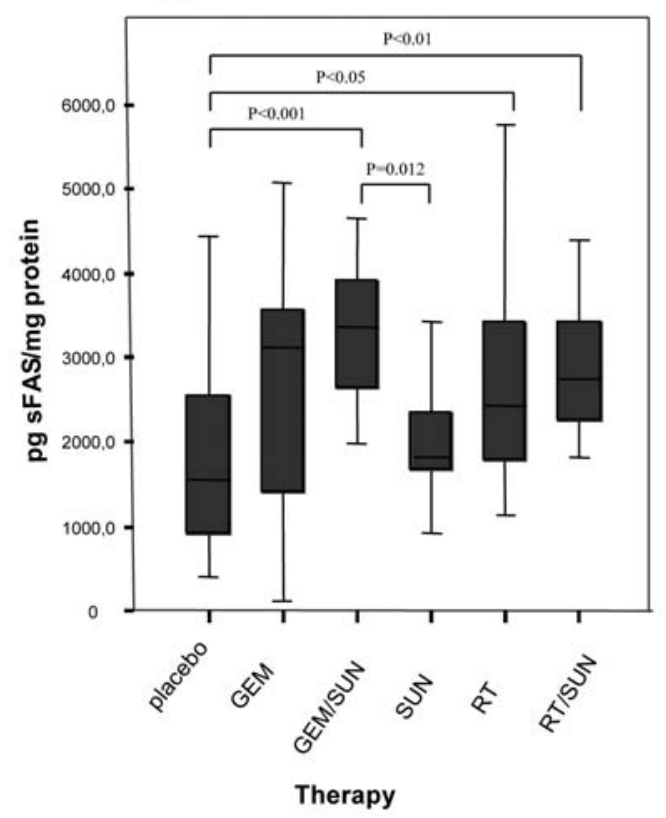

B

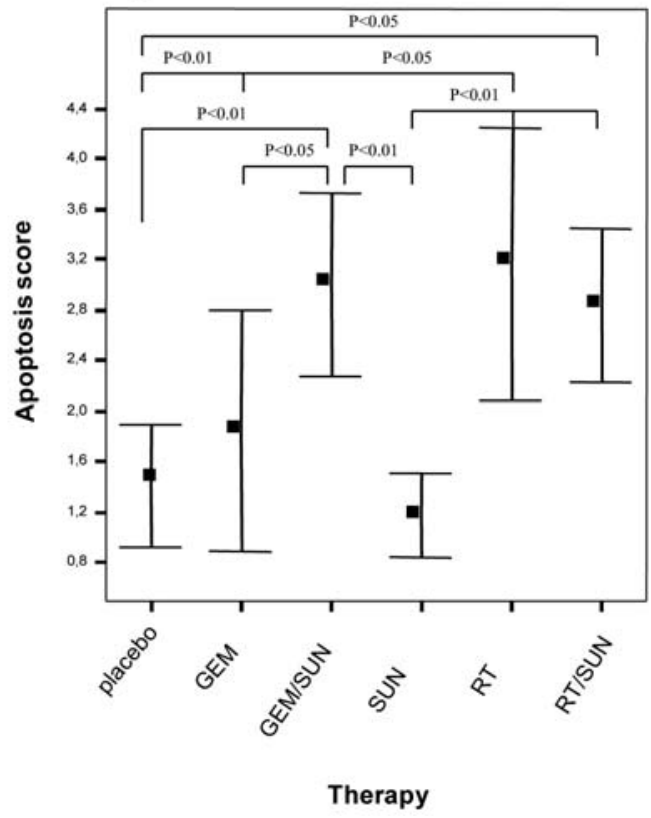

Figure 2. sFAS and cleaved caspase-3 per therapy. (A) sFAS (pg/mg protein), (B) Immunohistochemical scores cleaved caspase-3. Error bars show mean \pm standard error of the mean. GEM, gemcitabine; GEM/SUN, gemcitabine/sunitinib; SUN, sunitinib; RT, radiotherapy; RT/SUN, radiotherapy/sunitinib.

at room temperature with a labelled polymer-HRP anti-rabbit secondary antibody (DakoCytomation). The colour reaction was developed using the chromogen 3,3-diaminobenzidine+ (DAB) (DakoCytomation) for $10 \mathrm{~min}$. After washing, the tissue sections were counterstained with Mayer's haematoxylin. TBS $/ 0.1 \%$ Tween $/ 5 \%$ normal goat serum instead of the primary antibody was used as negative control on each slide in order to exclude false positive responses from non-specific binding of the secondary antibody. For the quantification of degree of apoptosis, 2 different readers (VC, PDM) first 'scanned' the entire tumor section at low power (magnification, $x 40$ ) to obtain a global view per tumor (qualitative assessment). The number of apoptotic bodies was then counted in at least ten high power fields (magnification, $\mathrm{x} 200$ ) per tumor slice to obtain an individual score for degree of apoptosis (quantitative assessment). Per treatment group a mean score was calculated and this value was used for further analysis.

Prior to staining the specimens, an isotype control was performed to estimate the non-specific binding of target primary antibodies to cell surface antigens.

Enzyme-linked immunoadsorbent assay (ELISA) for sFas, $V E G F, E G F$, placental growth factor $(P l G F)$. Protein lysates from fresh frozen tissues $(\mathrm{n}=113)$ were extracted with RIPA buffer $(2.5 \mathrm{mM}$ Tris, $50 \mathrm{mM} \mathrm{NaCl}, 0.5 \% \mathrm{NP} 40,0.5 \%$ deoxycholate, $0.1 \%$ SDS, $0.555 \mathrm{~g} / \mathrm{ml} \beta$-glycerophosphate, $1 \mathrm{mM}$ DTT, $20 \mu 1 \mathrm{mini}$ EDTA-free protease inhibitor cocktail). Total protein was determined with a Biorad DC protein assay kit (Biorad, Nazareth, Belgium) and absorbance was measured on a plate reader with a 630-nm long-pass filter.

VEGF-A, EGF, PIGF and sFas levels were determined by commercially available kits from R\&D Systems (Abingdon, UK) according to the manufacturer's instructions.

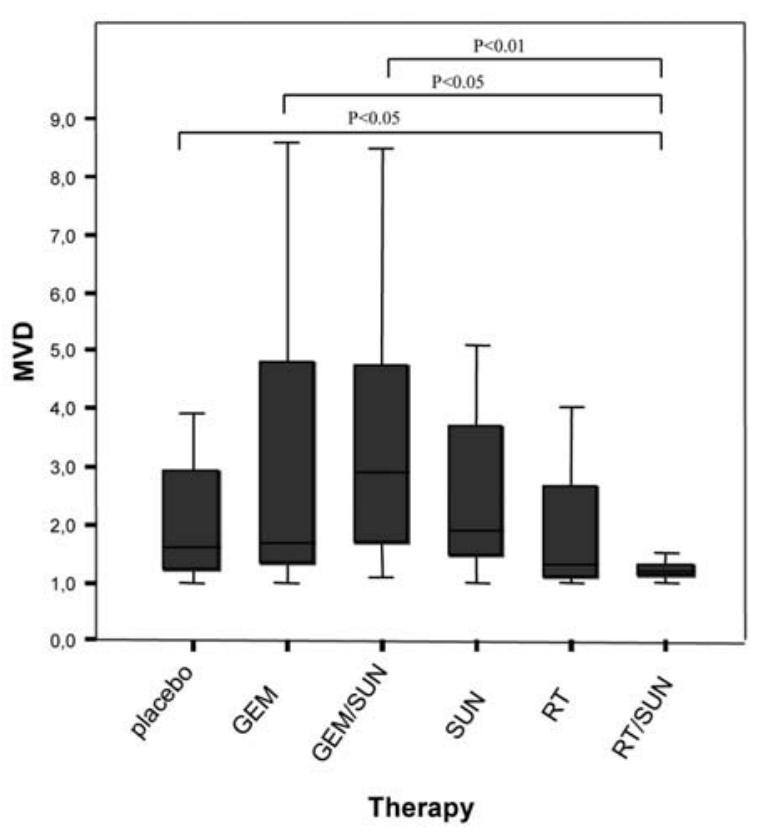

Figure 3. Microvessel density per therapy. MVD, microvessel density; GEM, gemcitabine; GEM/SUN, gemcitabine/sunitinib; SUN, sunitinib; RT, radiotherapy; RT/SUN, radiotherapy/sunitinib.

Statistics. All statistics were calculated using SPSS for Windows, version 15.0. Kolmogorov-Smirnov test was used to check on normality of data distribution. Differences between groups were assessed using analysis of variance (ANOVA and post-hoc LSD comparisons) in case of normal distributed data. Kruskal-Wallis test was used to compare groups in case of departure from normality. Correction for multiple comparisons (Bonferroni) was applied. Significance was defined as $\mathrm{P}<0.05$. 

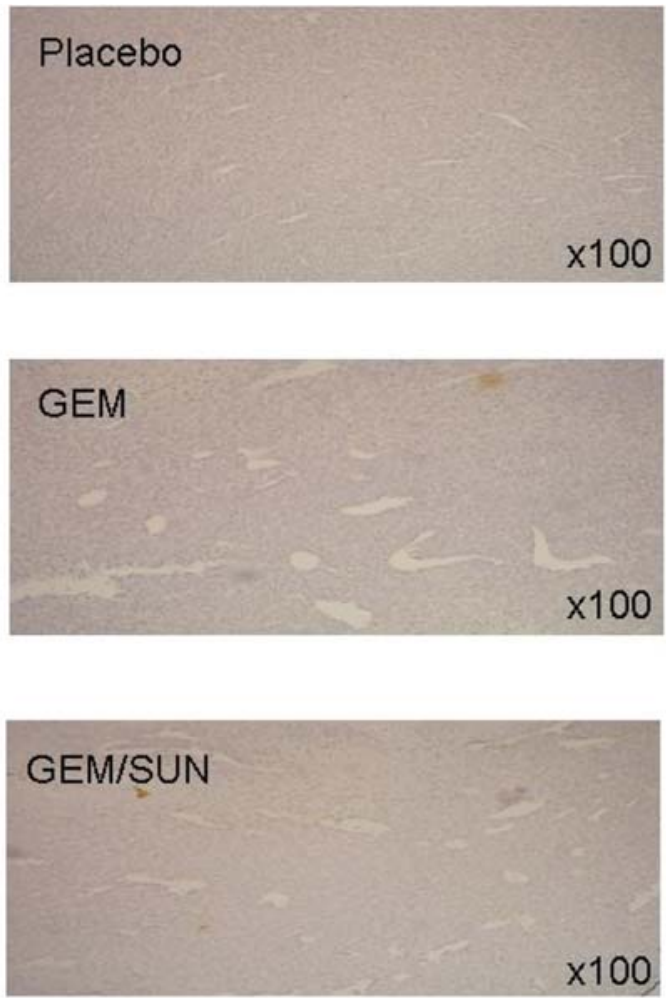
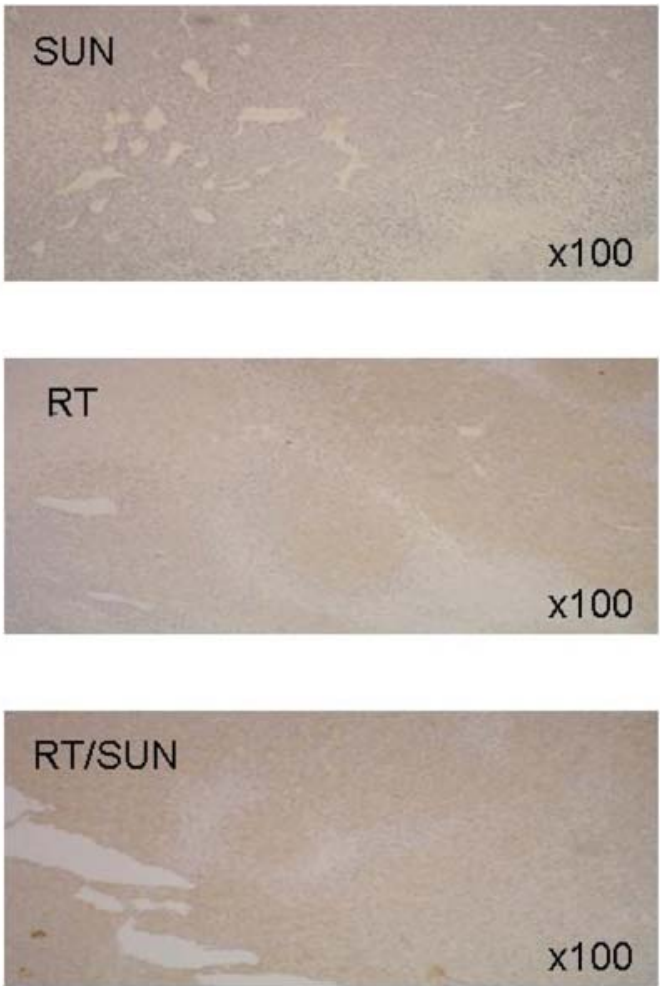

Figure 4. MVD (CD31 staining). GEM, gemcitabine; GEM/SUN, gemcitabine/sunitinib; SUN, sunitinib; RT, radiotherapy; RT/SUN, radiotherapy/sunitinib; magnification, $\mathrm{x} 100$

\section{Results}

Treatment with placebo, gemcitabine (GEM), gemcitabine+ sunitinib (GEM/SUN), sunitinib (SUN), radiotherapy (RT), radiotherapy + sunitinib $(R T / S U N)$ : Effect of different treatment strategies on tumor growth. One million Panc02 cells were injected in the right hind leg of 222 mice. Tumors became clearly visible after a median of 7 days after inoculation (range 6-17 days). Mice were randomly stratified into different treatment groups and underwent i.p. therapy during 1 week. Mice were sacrificed 14 days after the start of therapy. No significant differences in body weight were found between treatment and control groups, and no toxic reactions occurred.

Tumor growth curve. The tumor growth curve is shown in Fig. 1. Although randomized, tumors in the RT group were larger at day 0 than in other groups $(\mathrm{P}<0.001$, see Table I). At day 14 , tumors in all groups had grown significantly despite treatment. Only in RT/SUN treated mice tumor growth was retarded, however, the enlargement was still significant $(\mathrm{P}=0.033)$.

Apoptosis: Expression of sFas and cleaved caspase-3 in different treatment groups sFAS (Fig. 2A). Highest levels of sFAS were seen in GEM/SUN, RT/SUN and RT treated mice. This was significantly higher than in the placebo group $(\mathrm{P}<0.001, \mathrm{P}<0.01$ and $\mathrm{P}<0.05$ respectively, ANOVA, LSD post hoc comparison). sFAS levels in GEM/SUN mice were significantly higher than in SUN treated mice $(\mathrm{P}=0.012)$. No difference was seen between placebo mice and GEM or SUN treated mice $(\mathrm{P}>0.05)$.
Cleaved caspase-3 (Fig. 2B). Highest degrees of apoptosis were seen in GEM/SUN, RT and RT/SUN treated mice (no significant difference between these 3 groups). The degree of apoptosis in GEM/SUN, RT and RT/SUN was significantly higher compared to placebo $(\mathrm{P}<0.01)$ and GEM $(\mathrm{P}<0.05)$. Lower grade of apoptosis was detected in the GEM, SUN and placebo group (no significant difference between these 3 groups).

Microvessel density (MVD). Lowest MVD was seen in RT/SUN treated mice, which was significantly lower than in the placebo group $(\mathrm{P}<0.05)$, GEM $(\mathrm{P}<0.05)$ and GEM/SUN group $(\mathrm{P}<0.01$, Fig. 3). Differences between other groups were not significant after Bonferroni correction. Examples of CD31 staining for different treatment arms are given in Fig. 4.

Expression of VEGF, PlGF and EGF in different treatment groups (Table II, Fig. 5).

$V E G F$. Lowest levels of VEGF were found in placebo, SUN, GEM and GEM/SUN groups (no significant difference between these 4 groups). Highest VEGF levels were seen in RT and RT/SUN mice, which was significantly higher compared to placebo $(\mathrm{P}<0.001)$ and other treatment groups $(\mathrm{P}<0.01$ for all comparisons, ANOVA, LSD post hoc comparison). VEGF level was not significantly different between RT and RT/ SUN groups.

$P l G F$. Lowest levels of PlGF were found in placebo, RT and RT/SUN treated mice (no significant difference between these 3 groups). Highest levels of PIGF were observed after GEM and SUN treatment. PIGF level after GEM therapy was 

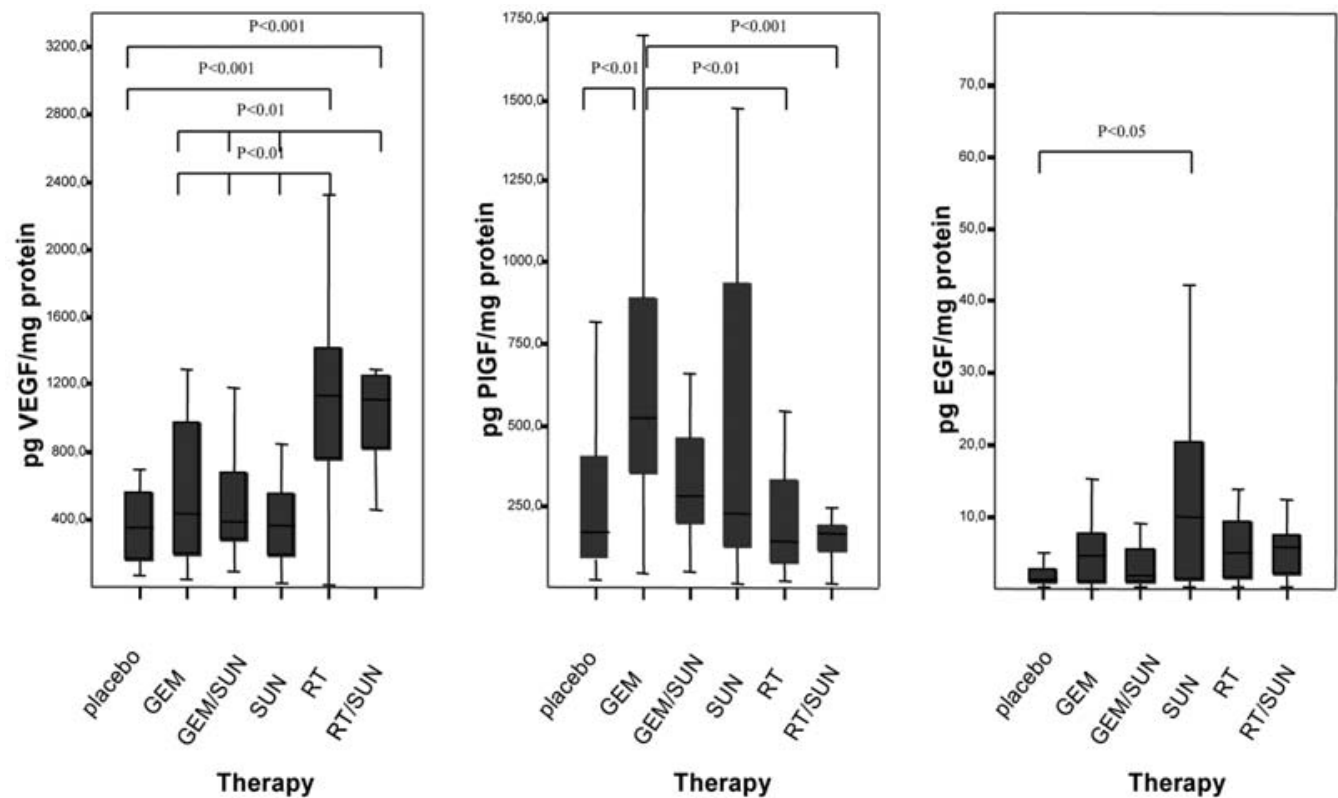

Figure 5. VEGF, PIGF and EGF per therapy group. Left: VEGF (pg/mg protein), Middle: PlGF (pg/mg protein), Right: EGF (pg/mg protein); GEM, gemcitabine; GEM/SUN, gemcitabine/sunitinib; SUN, sunitinib; RT, radiotherapy; RT/SUN, radiotherapy/sunitinib.

Table II. Levels of VEGF, PIGF and EGF were measured by ELISA.

\begin{tabular}{|c|c|c|c|c|c|c|c|}
\hline & & Placebo & GEM & GEM/SUN & SUN & $\mathrm{RT}$ & RT/SUN \\
\hline Tumors & Total $=113$ & $(n=16)$ & $(n=22)$ & $(n=19)$ & $(n=21)$ & $(n=17)$ & $(n=18)$ \\
\hline \multirow[t]{2}{*}{ VEGF } & Minimum & 69.45 & 114.60 & 96.93 & 28.40 & 428.99 & 462.24 \\
\hline & Maximum & 699.93 & 2390.09 & 1176.91 & 1407.33 & 3266.11 & 2296.27 \\
\hline \multirow[t]{2}{*}{ PlGF } & Minimum & 27.29 & 41.26 & 48.60 & 11.59 & 16.70 & 14.46 \\
\hline & Maximum & 819.75 & 1698.44 & 1245.43 & 1472.30 & 731.42 & 367.01 \\
\hline \multirow[t]{2}{*}{ EGF } & Minimum & 0.10 & 0.01 & 0.13 & 0.27 & 0.09 & 0.19 \\
\hline & Maximum & 6.46 & 21.44 & 9.01 & 74.38 & 131.15 & 20.16 \\
\hline
\end{tabular}

VEGF, PIGF, EGF expressed in pg/mg protein extracted; GEM, gemcitabine; GEM/SUN, gemcitabine/sunitinib; SUN, sunitinib; RT, radiotherapy; RT/SUN, radiotherapy/sunitinib.

significantly higher compared to placebo $(\mathrm{P}<0.01)$, RT $(\mathrm{P}<0.01)$ and $\mathrm{RT} / \mathrm{SUN}$ group $(\mathrm{P}<0.001)$. The difference between SUN treated mice and other groups did not reach statistical significance after Bonferroni correction. Intermediate levels of PlGF were found in GEM/SUN treated mice, but the difference with other groups was also not statistically significant.

$E G F$. Highest levels of EGF were found after treatment with SUN. These values were significantly higher than in the placebo-group $(\mathrm{P}<0.05)$. Other comparisons did not reach statistical significance after Bonferroni correction.

\section{Discussion}

Local recurrences and distal metastasis continue to impact survival in pancreatic cancer. Combining conventional cytotoxic drugs with novel targeted agents that specifically interfere with key pathways controlling cancer cell survival has gained wide interest in recent years. Therefore the aim of our study was to compare treatment effects of gemcitabine (GEM), sunitinib (SUN) and radiotherapy (RT) in a preclinical model of pancreatic adenocarcinoma.

It has already been shown in the past that administration of SUN leads to inhibition of VEGFR-, PDGFR-, KITphosphorylation $(25,28,35-37)$. Direct measures of VEGFand PDGF-receptor inhibition are difficult in clinical settings. In vivo, tumors are exposed to a complex mixture of growth factors, stimulating multiple signaling pathways, including those not inhibited by the administered therapy. All these growth factors can stimulate both tumor cells and endothelial cells in an autocrine/paracrine way (38). In the present study, the presence of proangiogenic proteins was quantified by ELISA: VEGF-A and PIGF as ligands for VEGFR and EGF as a ligand for EGFR. Recently, SUN was used in bevacizumab-refractory renal cell carcinoma and VEGF-A, VEGF-C, 
soluble VEGF receptor [sVEGFR]-3 and PIGF were measured as biomarkers (39). Mean plasma VEGF-A and PIGF levels significantly increased whereas VEGF-C and sVEGFR-3 levels decreased with SUN treatment. Lower baseline levels of sVEGFR-3 and VEGF-C were associated with longer progression-free survival and objective response rate. These baseline levels may have potential utility as biomarkers of clinical efficacy in this setting.

Immunohistochemical staining for CD31 was used as surrogate marker of tissue hypoxia and effect on vessel density. Cleaved caspase- 3 and sFAS were used as markers of apoptosis. As measured by these biomarkers, combined treatments have some advantages over either therapy alone. Highest degrees of apoptosis were seen in GEM/SUN, RT and RT/SUN treated mice. It is possible that apoptosis and cytotoxic damage to tumor cells caused by RT and conventional chemotherapeutics like GEM, might have been exacerbated through inhibition of tumor-supporting stroma and blood vessels by SUN. Antiangiogenic treatments directly target angiogenic endothelial cells (ECs) that line tumor blood vessels and lead to their destruction. In addition, some treatments target non-endothelial cells like tumor cells or smooth muscle cells. The latter two can release prosurvival factors such as VEGF that renders ECs more resistant to cytotoxic treatments. Targeting these non-endothelial cells might therefore increase the sensitivity of ECs to radiotherapy and chemotherapy $(40,41)$. Although, adding radiotherapy to antiangiogenic treatment does not seem logical. A decrease in tumor vessel density induced by antiangiogenic drugs would be expected to reduce tumor perfusion and thereby oxygen delivery (42). However, it has already been shown in the past that antiangiogenic treatment induces destruction of immature and inefficient vessels and promotes maturation of the remaining vessels (43).

After ionizing radiation, hypoxia inducible factor-1 (HIF-1) will promote tumor cells to express cytokines (like VEGF) that have radioprotective effects on neighboring ECs (44). Also in our study, we found a substantial release of VEGF after radiation. These cytokines send antiapoptotic signals to tumor vessels, making them resistant to radiation. Blocking these cytokines (like VEGF) can dramatically increase the radiosensitivity of tumor vasculature leading to elevated overall tumor radioresponsiveness (45). Congruent with this theory, the largest reduction in tumor growth and MVD was observed in the RT/SUN group. So these findings suggest that adding SUN to RT leads to an effective pruning of (immature) vessels, rendering this therapy regimen more efficient than RT alone.

Placental growth factor (PlGF), a VEGF homolog, is a pleiotropic cytokine that stimulates EC growth, migration and survival (46). PIGF binds to VEGFR-1 and acts independent of VEGF in ECs and tumor cells, which primarily express VEGFR-1. Genetic studies show that PIGF is redundant for vascular development and maintenance, but contributes to the 'angiogenic switch' in disease (47). By upregulating PlGF, ECs amplify their responsiveness to VEGF during the 'angiogenic switch' in many pathological disorders. PlGF levels in plasma and tumors correlate with tumor stage, vascularity, recurrence, metastasis and survival in various tumors $(48,49)$. Of note, PlGF is up-regulated after anti-
VEGF therapy and gemcitabine $(26,50,51)$. These findings point to a role for PIGF in rapid restoration of tumor blood supply after treatment and thus, to enhanced likelihood of tumor regrowth. Also in our experiments, PlGF expression was induced by GEM monotherapy. Lowest levels were seen in RT and especially RT/SUN treated mice, suggesting that this rapid restoration of blood supply could have been prohibited in the latter 2 treatment groups. Prevention of this angiogenic response to treatment may require administration of antiangiogenic therapy during, rather than after radiotherapy treatment.

Multitargeted inhibitors like SUN provide the opportunity to attack tumor growth and survival by multiple mechanisms. Considering the fact that an escape mechanism via EGFsignaling might emerge in vivo, we determined levels of EGF protein in each tumor. EGF protects ECs from apoptosis both by directly acting on the EC compartment as well as via paracrine induction of survival factors (52). We found that EGF levels were elevated after SUN therapy, whereas in all other groups, this level remained at the placebo level. One possible explanation could be in the interaction between HIF- $1 \alpha$ and EGFR. Hypoxia and von HippelLindau tumor-suppressor protein control HIF-1 $\alpha$ stability and function, hereby regulating transcription of hypoxiainducible genes such as VEGF and PDGF. EGFR (ErbB1/2) receptor signaling plays an important role in the regulation of HIF-1 $\alpha$-mediated VEGF expression via the Ras/Raf/ MEK and PI3K/Akt pathways (53). Therefore, dual inhibition of EGFR signaling and VEGF/PDGF pathways might provide a better therapeutic benefit than either agent alone and could overcome resistance to EGFR-targeted therapies.

Recently, similar findings were reported in vitro and in vivo $(28,34)$. Sunitinib was shown to sensitize ECs to the cytotoxic effects of ionizing radiation. Similar to our findings, combined treatment with RT/SUN delayed tumor growth, by enhanced destruction of tumor vasculature (MVD) in addition to enhanced killing of pancreatic cancer cells. In addition, in the present study we showed that GEM/SUN combination therapy has superior proapoptotic activity. Adding RT or GEM to SUN seems to intensify the antitumor effect of either therapy alone. Our study also suggests that treatment modulates circulating VEGF pathway biomarkers like VEGF, PIGF and EGF. Further studies are needed to define whether these changes may have potential utility as biomarkers of clinical efficacy in this setting.

In conclusion, this study describes a murine model of pancreatic cancer, where combined treatment with RT/SUN and GEM/SUN has advantages over RT, GEM and SUN alone. Multitargeted angiogenesis inhibitor therapy with sunitinib combined with either radiotherapy or gemcitabine may be a novel approach for human pancreatic cancer.

\section{Acknowledgements}

The authors thank Professor Marc Bracke (Department of Experimental Cancerology, Ghent University Hospital) for the cell culture infrastructure. V.C. is supported by a Bijzonder Onderzoeksfonds (code 011D14103) of Ghent University. M.P. is Senior Clinical Investigator of the Research FoundationFlanders, Belgium. 


\section{References}

1. Jemal A, Siegel R, Ward E, Murray T, Xu J and Thun MJ: Cancer statistics, 2007. CA Cancer J Clin 57: 43-66, 2007.

2. Nitecki SS, Sarr MG, Colby TV and van Heerden JA: Longterm survival after resection for ductal adenocarcinoma of the pancreas: is it really improving? Ann Surg 221: 59-66, 1995.

3. Piorkowski RJ, Blievernicht SW, Lawrence W Jr, Madariaga J, Horsley JS III, Neifeld JP and Terz JJ: Pancreatic and periampullary carcinoma. Experience with 200 patients over a 12-year period. Am J Surg 143: 189-193, 1982.

4. Gudjonsson B: Cancer of the pancreas: 50 years of surgery. Cancer 60: 2284-2303, 1987.

5. Tepper J, Nardi G and Sutt H: Carcinoma of the pancreas: review of MGH experience from 1963-1973-analysis of surgical failure and its implications for radiation therapy. Cancer 37: 1519-1524, 1976.

6. Griffin JF, Smalley SR, Jewell W, Paradelo JC, Reymond RD, Hassanein RE and Evans RG: Patterns of failure after curative resection of pancreatic carcinoma. Cancer 66: 56-61, 1990.

7. Li D, Xie K, Wolff R and Abbruzzese JL: Pancreatic cancer. Lancet 363: 1049-1057, 2004.

8. Oettle $\mathrm{H}$ and Neuhaus P: Adjuvant therapy in pancreatic cancer. Drugs 67: 2293-2310, 2007

9. Moertel CG, Frytak S, Hahn RG, O'Connell MJ, Reitemeier RJ, Rubin J, Schutt AJ, Weiland LH, Child DS, Holbrook MA, Lavin PT, Livstone E, Spiro H, Knowlton A, Kasler M, Barkin J, Lessner H, Mann-Kaplan R, Ramming K, Douglas HO Jr, Thomas P, Nave H, Bateman J, Lokich J, Brooks J, Chaffey J, Corson JM, Zamcheck N and Novak JW: Therapy of locally unresectable pancreatic carcinoma: a randomized comparison of high dose (6000 rads) radiation alone, moderate dose radiation (4000 rads + 5-fluorouracil), and high dose radiation + 5fluorouracil: the Gastrointestinal Tumor Study Group. Cancer 48: 1705-1710, 1981.

10. Klinkenbijl JH, Jeekel J, Sahmoud T, van Pel R, Couvreur ML, Veenhof CH, Arnaud JP, Gonzalez DG, de Wit LT, Hennipman A and Wils J: Adjuvant radiotherapy and 5-fluorouracil after curative resection of cancer of the pancreas and periampullary region: phase III trial of the EORTC gastrointestinal tract cancer cooperative group. Ann Surg 230: 776-782, 1999.

11. Neoptolemos JP, Stocken DD, Friess H, Bassi C, Dunn JA, Hickey H, Beger H, Fernandez-Cruz L, Dervenis C, Lacaine F, Falconi M, Pederzoli P, Pap A, Spooner D, Kerr DJ and Büchler MW: A randomized trial of chemoradiotherapy and chemotherapy after resection of pancreatic cancer. N Engl J Med 350: 1200-1210, 2004.

12. Regine WF, Winter KA, Abrams RA, Safran H, Hoffman JP, Konski A, Benson AB, Macdonald JS, Kudrimoti MR, Fromm ML, Haddock MG, Schaefer P, Willett CG and Rich TA: Fluorouracil vs gemcitabine chemotherapy before after fluorouracil-based chemoradiation following resection of pancreatic adenocarcinoma: a randomized controlled trial. JAMA 299: 1019-1026, 2008.

13. Oettlle H, Post S, Neuhaus P, Gellert K, Langrehr J, Ridwelski K, Schramm H, Fahlke J, Zuelke C, Burkart C, Gutberlet K, Kettner E, Schmalenberg H, Weigang-Koechler K, Bechstein WO, Niedergethmann M, Schmidt-Wolf I, Roll L, Doerken B and Riess H: Adjuvant chemotherapy with gemcitabine vs observation in patients undergoing curative-intent resection of pancreatic cancer: a randomized controlled trial. JAMA 297: 267-277, 2007.

14. Yeo CJ, Cameron JL, Lillemoe KD, Sohn TA, Campbell KA, Sauter PK, Coleman J, Abrams RA and Hruban RH: Pancreaticoduodenectomy with or without distal gastrectomy and extended retroperitoneal lymphadenectomy for periampullary adenocarcinoma, part 2: randomized controlled trial evaluating survival, morbidity and mortality. Ann Surg 236: 355-366, 2002.

15. Li CP, Chao Y, Chi KH, Chan WK, Teng HC, Lee RC, Chang FY, Lee SD and Yen SH: Concurrent chemoradiotherapy treatment of locally advanced pancreatic cancer: gemcitabine versus 5fluorouracil, a randomized controlled study. Int J Radiat Oncol Biol Phys 57: 98-104, 2003.

16. Burris HA III, Moore MJ, Andersen J, Green MR, Rothenberg ML, Modiano MR, Cripps MC, Portenoy RK, Storniolo AM, Tarassoff P, Nelson R, Dorr FA, Stephens CD and Von Hoff DD: Improvements in survival and clinical benefit with gemcitabine as first-line therapy for patients with advanced pancreas cancer: a randomized trial. J Clin Oncol 15: 2403-2413, 1997.
17. Ducreux M, Boige V, Goéré D, Deutsch E, Ezra P, Elias D and Malka D: Pancreatic cancer: From pathogenesis to cure. Best Pract Res Clin Gastroenterol 21: 997-1014, 2007.

18. Kindler HL, Niedzwiecki D, Hollis D, Oraefo E, Schrag H, Hurwitz H, McLeod HL, Mulcahy MF, Schilsky RL and Goldberg RM: A double-blind, placebo-controlled, randomized phase III trial of gemcitabine (G) plus bevacizumab (B) versus gemcitabine plus placebo $(\mathrm{P})$ in patients with advanced pancreatic cancer (PC): a preliminary analysis of Cancer and Leukemia Group B (CALGB) 80303 [abstract]. J Clin Oncol 25 (Suppl): 4508, 2007.

19.Philip PA, Benedetti C, Fenoglio-Preiser C, Zalupski M, Lenz H, O'Reilly E, Wong R, Atkins J, Abruzzese J and Blanke C: Phase III study of gemcitabine $(G)$ plus cetuximab (C) versus gemcitabine in patients (pts) with locally advanced or metastatic pancreatic adenocarcinoma (PC): SWOG S025 study [abstract]. J Clin Oncol 25 (Suppl): LBA4509, 2007.

20. Moore MJ, Goldstein D, Hamm J, Figer A, Hecht JR, Gallinger S, Au HJ, Murawa P, Walde D, Wolff RA, Campos D, Lim R, Ding K, Clark G, Voskoglou-Nomikos T, Ptasynski M and Parulekar W: Erlotinib plus gemcitabine compared with gemcitabine alone in patients with advanced pancreatic cancer: a phase III trial of the National Cancer Institute of Canada Clinical Trials Group. J Clin Oncol 25: 1960-1966, 2007.

21. Relf M, LeJeune S, Scott PA, Fox S, Smith K, Leek R, Moghaddam A, Whitehouse R, Bicknell R and Harris AL: Expression of the angiogenic factors vascular endothelial cell growth factor, acidic and basic fibroblast growth factor, tumor growth factor beta-1, platelet-derived endothelial cell growth factor, placenta growth factor, and pleiotrophin in human primary breast cancer and its relation to angiogenesis. Cancer Res 57: 963-969, 1997.

22. Willett CG, Kozin SV, Duda DG, di Tomaso E, Kozak KR, Boucher Y and Jain RK: Combined vascular endothelial growth factor-targeted therapy and radiotherapy for rectal cancer: theory and clinical practice. Semin Oncol 33 ( Suppl 10): S35-S40, 2006.

23. Crane CH, Ellis LM, Abbruzzese JL, Amos C, Xiong HQ, Ho L, Evans DB, Tamm EP, Ng C, Pisters PW, Charnsangavej C, Delclos ME, O'Reilly M, Lee JE and Wolff RA: Phase I trial evaluating the safety of bevacizumab with concurrent radiotherapy and capecitabine in locally advanced pancreatic cancer. J Clin Oncol 24: 1145-1151, 2006.

24. Krempien R, Munter MW, Timke C, Friess H, Hartung G, Herfarth KK, Abdollahi A, Buchler MW, Huber PE and Debus J: Cetuximab in combination with intensity modulated radiotherapy (IMRT) and gemcitabine for patients with locally advanced pancreatic cancer: a prospective phase II trial [PARCStudy ISRCTN56652283] [abstract]. J Clin Oncol 25 (Suppl): 4573,2007

25. Mendel DB, Laird AD, Xin X, Louie SG, Christensen JG, Li G, Schreck RE, Abrams TJ, Ngai TJ, Lee LB, Murray LJ, Carver J, Chan E, Moss KG, Haznedar JO, Sukbuntherng J, Blake RA, Sun L, Tang C, Miller T, Shirazian S, McMahon G and Cherrington JM: In vivo antitumor activity of SU11248, a novel tyrosine kinase inhibitor targeting vascular endothelial growth factor and platelet-derived growth factor receptors: determination of a pharmacokinetic/pharmacodynamic relationship. Clin Cancer Res 9: 327-337, 2003.

26. Motzer RJ, Michaelson MD, Redman BG, Hudes GR, Wilding G, Figlin RA, Ginsberg MS, Kim ST, Baum CM, DePrimo SE, Li JZ, Bello CL, Theuer CP, George DJ and Rini BI: Activity of SU11248, a multitargeted inhibitor of vascular endothelial growth factor receptor and platelet-derived growth factor receptor, in patients with metastatic renal cell carcinoma. J Clin Oncol 24: 16-24, 2006.

27. Demetri GD, van Oosterom AT, Garrett CR, Blackstein ME, Shah MH, Verweij J, McArthur G, Judson IR, Heinrich MC, Morgan JA, Desai J, Fletcher CD, George S, Bello CL, Huang X, Baum CM and Casali PG: Efficacy and safety of sunitinib in patients with advanced gastrointestinal stromal tumor after failure of imatinib: a randomised controlled trial. Lancet 368: 1329-1338, 2006.

28. Schueneman AJ, Himmelfarb E, Geng L, Tan J, Donnelly E, Mendel D, McMahon G and Hallahan DE: SU11248 maintenance therapy prevents tumor regrowth after fractionated irradiation of murine tumor models. Cancer Res 63: 4009-4016, 2003. 
29. Abrams TJ, Murray LJ, Pesenti E, Holway VW, Colombo T, Lee LB, Cherrington JM and Pryer NK: Preclinical evaluation of the tyrosine kinase inhibitor SU11248 as a single agent and in combination with 'standard of care' therapeutic agents for the treatment of breast cancer. Mol Cancer Ther 2: 1011-1021, 2003.

30. Fujimoto K, Hosotani R, Wada M, Lee JU, Koshiba T, Miyamoto Y, Tsuji S, Nakajima S, Doi R and Imamura M: Expression of two angiogenic factors, vascular endothelial growth factor and platelet-derived endothelial cell growth factor in human pancreatic cancer, and its relationship to angiogenesis. Eur J Cancer 34: 1439-1447, 1998

31. Yeh TS, Jan YY, Chiu CT, Ho YB, Chen TC, Lee KF, Chan KM, Hsu JC, Hwang TL and Chen MF: Characterisation of oestrogen receptor, progesterone receptor, trefoil factor 1 , and epidermal growth factor and its receptor in pancreatic cystic neoplasms and pancreatic ductal adenocarcinoma. Gut 51: 712-716, 2002.

32. Korc M: Pancreatic cancer-associated stroma production. Am J Surg 194: S84-S86, 2007.

33. Chang YT, Chang MC, Wei SC, Tien YW, Hsu C, Liang PC, Tsao PN, Jan IS and Wong JM: Serum vascular endothelial growth factor/soluble vascular endothelial growth factor receptor 1 ratio is an independent prognostic marker in pancreatic cancer. Pancreas 37: 145-150, 2008.

34. Cuneo KC, Geng L, Fu A, Orton D, Hallahan DE and Chakravarthy AB: SU11248 (sunitinib) sensitizes pancreatic cancer to the cytotoxic effects of ionizing radiation. Int J Radiat Oncol Biol Phys 71: 873-879, 2008.

35. Abrams TJ, Lee LB, Murray LJ, Pryer NK and Cherrington JM: SU11248 inhibits KIT and platelet-derived growth factor receptor beta in preclinical models of human small cell lung cancer. Mol Cancer Ther 2: 471-478, 2003.

36. Osusky KL, Hallahan DE, Fu A, Ye F, Shyr Y and Geng L: The receptor tyrosine kinase inhibitor SU11248 impedes endothelial cell migration, tubule formation, and blood vessel formation in vivo, but has little effect on existing tumor vessels. Angiogenesis 7: 225-233, 2004

37. Potapova O, Laird AD, Nannini MA, Barone A, Li G, Moss KG, Cherrington JM and Mendel DB: Contribution of individual targets to the antitumor efficacy of the multitargeted receptor tyrosine kinase inhibitor SU11248. Mol Cancer Ther 5: 1280-1289, 2006.

38. Tzeng CW, Frolov A, Frolova N, Jhala NC, Howard JH, Vickers SM, Buchsbaum DJ, Heslin MJ and Arnoletti JP: EGFR genomic gain and aberrant pathway signaling in pancreatic cancer patients. J Surg Res 143: 20-26, 2007.

39. Park JS, Qiao L, Su ZZ, Hinman D, Willoughby K, McKinstry R, Yacoub A, Duigou GJ, Young CS, Grant S, Hagan MP, Ellis E, Fisher PB and Dent P: Ionizing radiation modulates vascular endothelial growth factor (VEGF) expression through multiple mitogen activated protein kinase dependent pathways. Oncogene 20: 3266-3280, 2001.

40. Rini BI, Michaelson MD, Rosenberg JE, Bukowski RM, Sosman JA, Stadler WM, Hutson TE, Margolin K, Harmon CS, DePrimo SE, Kim ST, Chen I and George DJ: Antitumor activity and biomarker analysis of sunitinib in patients with bevacizumab-refractory metastatic renal cell carcinoma. J Clin Oncol 26: 3743-3748, 2008 .

41. Gorski DH, Beckett MA, Jaskowiak NT, Calvin DP, Mauceri HJ, Salloum RM, Seetharam S, Koons A, Hari DM, Kufe DW and Weichselbaum RR: Blockage of the vascular endothelial growth factor stress response increases the antitumor effects of ionizing radiation. Cancer Res 59: 3374-3378, 1999.
42. Feron O: Targeting the tumor vascular compartment to improve conventional cancer therapy. Trends Pharmacol Sci 25: 536-542, 2004.

43. Jain RK: Molecular regulation of vessel maturation. Nat Med 9: 685-693, 2003.

44. Moeller BJ, Richardson RA and Dewhirst MW: Hypoxia and radiotherapy: opportunities for improved outcomes in cancer treatment. Cancer Metastasis Rev 26: 241-248, 2007.

45. Geng L, Donnelly E, McMahon G, Lin PC, Sierra-Rivera E, Oshinka $\mathrm{H}$ and Hallahan DE: Inhibition of vascular endothelial growth factor receptor signaling leads to reversal of tumor resistance to radiotherapy. Cancer Res 61: 2413-2419, 2001.

46. Kaplan RN, Riba RD, Zacharoulis S, Bramley AH, Vincent L, Costa C, MacDonald DD, Jin DK, Shido K, Kerns SA, Zhu Z, Hicklin D, Wu Y, Port JL, Altorki N, Port ER, Ruggero D, Shmelkov SV, Jensen KK, Rafii S and Lyden D: VEGFR1positive haematopoietic bone marrow progenitors initiate the pre-metastatic niche. Nature 438: 820-827, 2005.

47. Carmeliet P, Moons L, Luttun A, Vincenti V, Compernolle V, De Mol M, Wu Y, Bono F, Devy L, Beck H, Scholz D, Acker T, DiPalma T, Dewerchin M, Noel A, Stalmans I, Barra A, Blacher S, Vandendriessche T, Ponten A, Eriksson U, Plate KH, Foidart JM, Schaper W, Charnock-Jones DS, Hicklin DJ, Herbert JM, Collen D and Persico MG: Synergism between vascular endothelial growth factor and placental growth factor contributes to angiogenesis and plasma extravasation in pathological conditions. Nat Med 7: 575-583, 2001.

48. Wei SC, Tsao PN, Yu SC, Shun CT, Tsai-Wu JJ, Wu CH, Su YN Hsieh FJ and Wong JM: Placenta growth factor expression is correlated with survival of patients with colorectal cancer. Gut 54: 666-672, 2005

49. Parr C, Watkins G, Boulton M, Cai J and Jiang WG: Placenta growth factor is over-expressed and has prognostic value in human breast cancer. Eur J Cancer 41: 2819-2827, 2005.

50. Taylor AP, Rodriguez M, Adams K, Goldenberg DM and Blumenthal RD: Altered tumor vessel maturation and proliferation in placenta growth factor-producing tumors: potential relationship to post-therapy tumor angiogenesis and recurrence. Int J Cancer 105: 158-164, 2003.

51. Fischer C, Jonckx B, Mazzone M, Zacchigna S, Loges S, Pattarini L, Chorianopoulos E, Liesenborghs L, Koch M, De Mol M, Autiero M, Wyns S, Plaisance S, Moons L, van Rooijen N, Giacca M, Stassen JM, Dewerchin M, Collen D and Carmeliet P: Anti-PlGF Inhibits Growth of VEGF(R)-inhibitor-resistant tumors without affecting healthy vessels. Cell 131: 463-475, 2007.

52. Sini P, Wyder L, Schnell C, O'Reilly T, Littlewood A, Brandt R, Hynes NE and Wood J: The antitumor and antiangiogenic activity of vascular endothelial growth factor receptor inhibition is potentiated by ErbB1 blockade. Clin Cancer Res 11: 4521-4532, 2005.

53. Kim WY and Kaelin WG Jr: Molecular pathways in renal cell carcinoma - rationale for targeted treatment. Semin Oncol 33. 588-595, 2006. 